\title{
“AWAKENING TO INTERCOMPREHENSION AT SEA"- A NEW TRAINING TOOL FOR THE DEVELOPMENT OF MULTILINGUAL COMPREHENSION SKILLS FOR MARITIME STUDENTS
}

\author{
Laura Cizer, Mariana Boeru \\ Mircea cel Batran Naval Academy, Constanta, Romania \\ E-Mail: lauracizer@yahoo.co.uk
}

\begin{abstract}
This paper attempts to showcase the potential of an in-house textbook for practicing Intercomprehension (IC) in a purely maritime context. It encompasses most of the research work conducted by the authors within EU funded grants as well as beyond them. First, reference will be made to the theoretical framework scaffolding this endeavor, namely the definition of such concepts as IC, textbooks, and IC didactics, then the newly devised textbook will be assessed according to several criteria: description of the teaching material, targeted audience, book structure, duration and pace of the teaching/learning process, objectives, types of tasks and internal dynamics. Thus, learners are led to demonstrate comprehension of foreign languages which is facilitated by the presence of different communication channels (written texts, sounds, images, etc). Consequently, in the authors' vision, this exposure to the concept of IC will certainly facilitate the overcoming of communication and socializing problems that nowadays occur frequently on-board ships manned by multilingual and multicultural crews.
\end{abstract}

Key words: Intercomprehension, English language, textbook, learning and teaching languages, multilingualism, IC didactics

\section{INTRODUCTION}

Intercomprehension (or IC) - as a multilingual approach to teaching and learning languages - is at the core of multilingual and intercultural educational curricula. Since its beginnings in the didactics of languages (as of the '90s), this concept has been the subject of much research and continues to develop with the integration of new materials and educational tools based on new technologies. The contribution of technologies to language learning is essential since their integration in the field of languages particularly favors learners' interactions and autonomy.

Over the years, numerous authors have attempted to define IC (Cizer 2013); however, from the multitude of these definitions, we will retain the definition of IC as the ability of individuals to understand) one or more unknown but related languages (both written and spoken), by resorting to diverse and complex strategies in order to achieve the final goal within the interaction: getting to the gist of the message. With regard to textbooks, it is essential to mention that there are multiple definitions as well. (Textbook) \& (RadićBojanić 2016). While attempting to summarize this, and compile a complex definition to cover all aspects, it will sound like this: the textbook is a teaching aid and a didactic book that comes in a handy format and that is used in the teaching/learning process following a given methodology. 
While language didactics is a discipline that belongs to language sciences and is aimed at teaching and learning one or more languages, the IC didactics or didactics of multilingualism is presented as didactics of a group of languages in which languages interact with one another due to linguistic proximity. F. J. Meissner defines IC didactics as "transferential didactics" which implies the possibility to lead learners to establish the existing similarity relationships between and among languages based on another language (mother tongue or known language) in order to raise their awareness of languages and cultures as well. (Meissner 2004)

As a matter of fact, this new approach to language didactics is also supported by official documents in compliance with the European Union's multilingual policy. In 2001 the Council of Europe decided to promote multilingualism in the Common European Framework of Reference for Languages (CEFR) that revises language proficiency levels and puts greater emphasis on receptive skills (written and oral comprehension). It also promotes the use of similarities between neighboring languages in learning foreign languages. It is in this respect that IC between related languages responds to these expectations and prerogatives. Thus, language understanding is favored by temporarily excluding language production, and through a series of cognitive strategies, IC makes it possible to understand languages from the same family, such as Romance, Germanic or Slavic languages, and sometimes going even beyond same-language families.

There is this first mention ever that language knowledge is not stored in separate compartments, but that it constitutes a plural and complex whole in which languages evolve and interact. Finally, the great innovation of the CEFR lies in the acceptance of partial and non-homogenous skills in learners' progressive construction of their language learning towards multilingualism. Thus, even if a learner is able to understand a language without speaking it, this skill is still valued and acknowledged; this is one of the founding principles of IC.

It should also be stressed that the multilingual approach advocated in the Framework of Reference for Pluralistic Approaches to Languages and Cultures (FREPA) favors the IC didactics. Published in 2007 by the Council of Europe, FREPA is oriented, as its name suggests, towards plural approaches of language teaching/learning, more precisely on didactic principles and practices involving several languages and cultures. There are four of them: awakening to languages, intercultural approach, IC of related languages and integrated didactic approaches to different languages. IC is cited within and it carries its didactic valences, which prove its seminal importance in plural approaches. An entire paragraph is devoted to this concept on page 8:

"In the approach termed intercomprehension between related languages the learner works on two or more languages of the same linguistic family (Romance, Germanic, Slavic languages, etc.) in parallel - one of these languages being the learner's mother tongue, the language of education, or another language learnt previously. In this approach there is a systematic focus on receptive skills, as the development of comprehension is the most tangible way of using the knowledge of a related language to learn a new one. Of course, this does not exclude some added benefits for productive skills. In the second half of the 1990s there was innovative work in this area with adult learners, including university students, in France and other countries speaking Romance languages, but also in Germany, in Scandinavian, as well as in Slavonic countries. Many were supported at a European level through the programmes of the European Union. Examples of this approach are to be found in certain materials produced for awakening 
to language approaches, but in general there has been little development of intercomprehension for children." (FREPA 2018)

The competences described in FREPA should be part of any IC training. Indeed, the table of global competences indicates what learners need in order to carry out a plurilingual exchange, which is in fact that type of exchange where everyone speaks his/her language. For example, one can cite: competence in resolving conflicts, overcoming obstacles, clarifying misunderstandings, competence in negotiation, adaptation, or even mediation, the latter being a key component in the IC concept.

Despite the fact that this intercomprehensive approach is becoming more and more important, IC principles stick more to the theoretical level whereas still scarcely represented on the practical one. For instance, our inventory - even if partial - of such already existant IC materials revealed only one solid finding, i.e. Euromania - the first European textbook, and it addresses pupils aged 8-11.

The resources are free online on the above-mentioned website where one can access a textbook in the seven Romance languages, a recording of all the texts in the textbook, a teacher's manual, a forum, etc. As their creators pointed out : "Intercomprehension places a bet on the intelligence of the pupils, on their ability to link, connect, manipulate and explain the global and the specific organization of a set of languages. We tell pupils the truth: this is a multilingual world, and the only way to gain access to that world is to build true multilingualism. The only remaining issue is the didactic engineering process that will enable the transfer of efficient methods adapted to each level, from primary school to university." (Escude 2015)

It is actually from this point that we have picked up and devised our textbook for the maritime higher education students based on today's reality that just like Europe, a ship is a multicultural and multilingual space. And so a question instantly arose: Would it not be wise to start training our students at the Naval Academy of Constanta (but not only) in intercomprehension?

There are many IC-related competences that we considered relevant to build and develop in our students, such as knowing how to compare both language and cultural phenomena of different languages / cultures, how to perceive language/cultural proximity and distance, how to speak about languages and cultures (whether his/hers or others), how to use and transfer knowledge from one language to another in order to grasp the meaning understand another language, how to interact and most importantly still, learning how to learn.

Thus, they will be able to deal with their onboard tasks more professionally. Taking into consideration this need, we collected our research results on intercomprehensive strategies that are useful for fostering better relationships and interactions onboard ships.

\section{TEXTBOOK DESCRIPTION}

The textbook titled "Awakening to Intercomprehension at Sea" (ATIS) was published at Mircea cel Batran Naval Academy Publishing House in 2017. This textbook is an invitation to comparative reflections between several languages with the declared purpose of laying the foundations for 
the acquisition of several IC strategies to be used for message decoding during interactions. With its relevant activities for practicing the notion of IC, the textbook creates a purely maritime context since it was intended as a working instrument with and for students preparing to enter the field of navigation, who will work on board ships with multilingual and multicultural crews. Its authors believe that it is an original and up-todate book that supports all those who want to better understand the phenomenon of IC, which is still inadequately studied in and outside Romania. In the specialist literature there are numerous theoretical studies, articles, books, presentations at international conferences, but not enough materials for individual or classroom study.

Its title was somehow inspired by one of the four competences stated in FREPA (see Introduction above) on the one hand, on the other hand, by INTERMAR - a European Cooperation Project funded by the EU Commission's Lifelong Learning Programme, under Key Action 2 of the Transversal Programme in which the authors also took part during 2011-2013. (Project)

The photo on the front cover (taken by one of the authors during her stay in the USA) has also been chosen to be in perfect accordance with the title. Indeed, the $22 \mathrm{~m}$-statue is named The Awakening and it actually represents a giant embedded in the earth, struggling to free himself, located at National Harbor in Prince George's County, Maryland, USA, just outside the District of Columbia. It was also intended to act as a metaphor for the concept of IC: people discover ways of communicating with each other using their different native languages, try to understand each other in their effort "to coconstruct meaning when different languages get in contact and pragmatically use it (IC, our remark) in a specific communicative situation." (Capucho 2004)

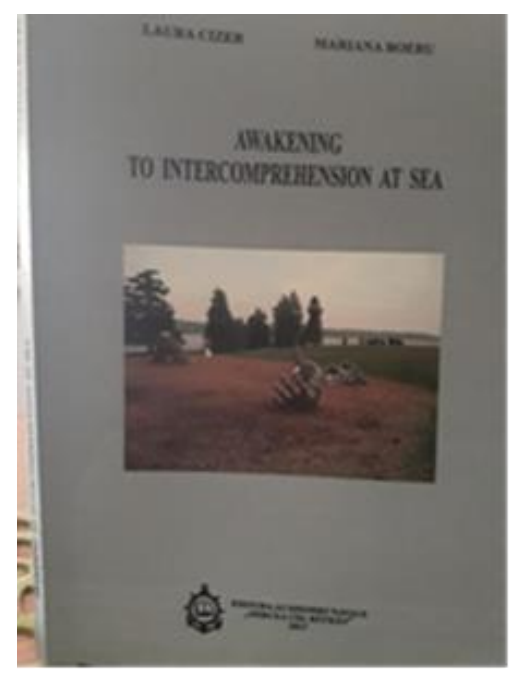

Fig. 1 Snapshot of the textbook cover

As far as the organization is concerned, ATIS starts with a theoretical framework and a review of different approaches to IC. This framing helps the user to determine the theoretical background to the process and to see how the term has appeared and evolved in dictionaries and other works of reference, as well as the actual changes in approaching 
the concept. Furthermore, there is a review of all research projects that have successfully addressed the concept of IC, thus providing its users with additional reasons for considering it as an effective means of language learning.

The textbook is divided into 9 chapters, plus a list containing the references that have been used or consulted during its creation, a chapter entirely devoted to teachers (Teacher's Notes) with punctual remarks for each unit and a key to exercises. The chapters are as follows: 1. Discovering Intercomprehension. Connecting Languages in the same Language Family; 2. Introduction to the Seven Sieves Method; 3. English as a Romance Language; 4. Discovering IC. 5. Going beyond the Limitations of a Single Language Family; 5. Practicing IC online: Ship Familiarization; 6. Intercomprehension at Sea; 7. Practicing IC at Sea through Sea Stories; 8. Captain Phillips. Practicing IC at Sea through Movies; and 9. Pir@cy: A Multilingual Response. Practicing IC at Sea through Webquests.

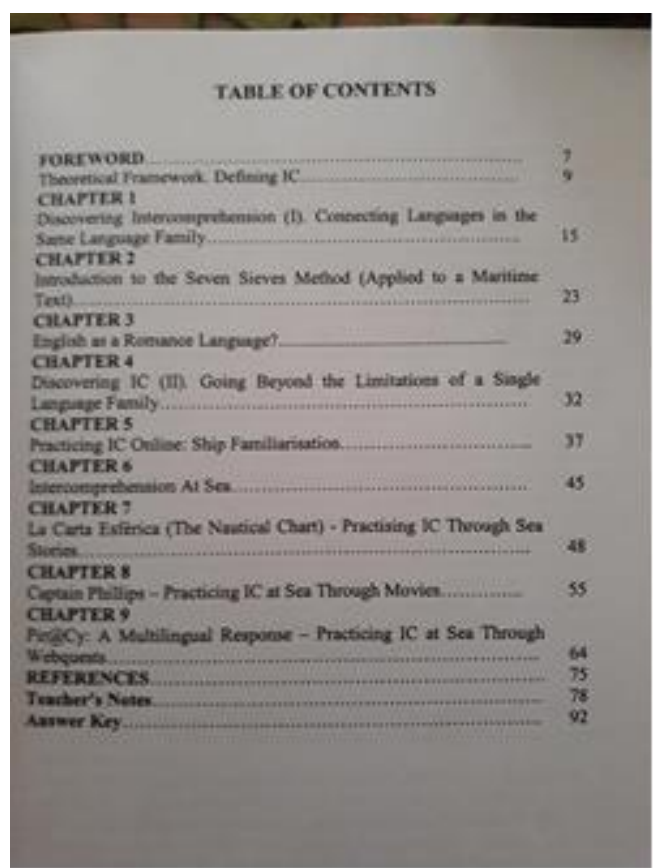

Fig. 2 Snapshot of the textbook table of contents

So, unlike other language methods which have distinct components such as the student's textbook/notebook, teacher's book, etc., ATIS gathers 3 elements all rolled in one: the actual textbook that can also be used as a notebook since there have been provided blank spaces for the learners to write down their answers, the teacher's notes containing useful instructions and suggestions to approach effectively each task, and the Answer Key which offers clear explanations and suggested answers. In addition, most of the activities rely on Internet links that need to be accessed in order to solve the tasks, or go entirely online, e.g. chapter 5. Practicing IC online: Ship Familiarization, chapter 8. Captain Phillips. Practicing IC at Sea through Movies; and chapter 9. Pir@cy: A 
Multilingual Response. Practicing IC at Sea through Webquests. Thus, the blended learning element is another innovative aspect of this textbook which makes it more effective, attractive and even amusing.

The instructions for task solving are clear and given in English which has been used as working and bridge language all throughout the way.

All chapters have been built around pedagogical scenarios. For instance, Chapter 1 is based on the 2012 maritime event: the Costa Concordia 2012 grounding and partial sinking, Chapter 6 features the main parts of a ship, Chapters 7 and 8 revolve around a sea story and respectively a well-known movie dealing with piracy, a highly poignant issue in the maritime community and paving the way to Chapter 9 for in-depth investigation into this hot topic.

The learner is immersed in a universe where s/he has to take on the challenge to solve the given tasks, and demonstrate proper use of strategies to accomplish them.

As for the typology of tasks, exercises and activities, they are quite varied : questions to prepare students for optimized deduction to grasp the meaning, drawing up a maritime glossary based on a given text in chapter 1, parallel-newspaper-article reading activity (chapter 2), retracing several basic maritime English terms back to their Latin origin, finding lexical/graphic similarities between terms in English and in Germanic languages (Danish, Dutch, German, Norwegian and Swedish) in chapter 3, making transfers and inferences in chapter 4, working on an online activity package embedded with sound, pictures and written texts in chapter 5, labelling parts of a ship correctly in several Romance languages and English, matching activities in chapter 6, labelling parts of a navigation instrument, questions based on the novel written by a Spanish writer - Arturo Perez-Reverte in chapter 7, questions based on the thriller movie Captain Phillips dubbed in several Romance languages in chapter 8 , and finding information on specific websites in chapter 9. These can be solved either in smaller or larger groups (whole class), in pairs or even individually.

\section{CONCLUSIONS}

"Awakening to Intercomprehension at Sea" seems to have interesting potentialities for practicing IC for learning purposes in a didactic framework as previously shown.

Through the diversity of its topics and the rich of vocabulary, it also addresses students regardless of their major and can be used both in the classroom under the teacher's guidance $r$ and as a self-study learning tool.

All in all, those who will engage in the study of this textbook will understand why IC is a methodological alternative to classical or traditional language learning and how it can provide users with practical communication in multilingual and cultural contexts that acknowledge diversity as a natural datum.

\section{REFERENCES}

ATIS - Cizer, L., Boeru, M. (2017). Awakening to Intercomprehension at Sea, Editura Academiei Navale Mircea cel Batran, Constanta

Capucho, F. "Línguas e identidades culturais: da implicação de politicos (socio)linguistas.” In Fábio L. da Silva \& Kanavillil Rajagopalan (orgs), 
A linguística que nos faz falhar. São Paulo: Unicamp: Parábola Editorial, 2004, p.83 -87 CEFR - https://rm.coe.int/1680459f97. Accessed on 5 November, 2018

Cizer, Laura, Intercomprehension - The Avatars of a Definition, In: Revista Annales UniversitatisApulensis. Series Philologica, 2013, Universitatea 1 Decembrie, Alba Iulia

Escude - https://laces.u-bordeaux.fr/wp-content/uploads/2015/12/2015-Escud\%C3\%A9learning-by-languages-Intercomprehension-and-Plurilinguism_Queens-College-NewYork.pdf Accessed on 5 November, 2018

Euromania - www.euro-mania.eu Accessed on 5 November, 2018

FREPA-https://carap.ecml.at/Teachertraining/FREPAAtrainingkit/tabid/2962/language /en-GB/Default.aspx Accessed on 5 November, 2018

Meissner, F-J. (2004). EuroComRom - Les sept tamis: lire les langues romanes dès le départ. Avec une introduction à la didactique de l'eurocompréhension. Aachen: Shaker, Editiones EuroCom, vol. 6

Project - http://www.intermar.ax/?page_id=6 Accessed on 5 November, 2018

Radić-Bojanić, Biljana B., Topalov, Jagoda P. - Textbooks in the EFL Classroom: Defining, Assessing and Analyzing. Retrieved from https://scindeksclanci.ceon.rs/data/pdf/0354-3293/2016/0354-32931603137R.pdf Accessed on 5 November, 2018

Textbook - http://edutechwiki.unige.ch/en/Textbook Accessed on 5 November, 2018 